\title{
Challenge of vegetation greening on water resources sustainability: Insights from a modeling-based analysis in Northwest China
}

\author{
Fei $\operatorname{Tian}^{1,2,3}$ (i) | Yi He Lü ${ }^{2}$ Bo Jie Fu ${ }^{2}$ Lu Zhang ${ }^{3}$ | Chuan fu Zang ${ }^{4}$ | Yong Hui Yang ${ }^{5}$ | \\ Guo Yu Qiu ${ }^{6}$
}

${ }^{1}$ Center for Agricultural Water Research in China, China Agricultural University, Beijing, China

${ }^{2}$ State Key Laboratory of Urban and Regional Ecology, Research Center for Eco-

Environmental Sciences, Chinese Academy of Sciences, Beijing, China

${ }^{3}$ CSIRO Land and Water Flagship, Canberra, Australia

${ }^{4}$ Forestry College of Inner Mongolia Agricultural University, Huhehaote, China

${ }^{5}$ Key Laboratory of Agricultural Water Resources, Center for Agricultural Resources Research, Institute of Genetics and Developmental Biology, Chinese Academy of Sciences, Shijiazhuang, China

${ }^{6}$ Key Laboratory for Urban Habitat Environment Science and Technology, School of Environment and Energy, Peking University, Shenzhen, China

\section{Correspondence}

Yi He Lü, State Key Laboratory of Urban and Regional Ecology, Research Center for EcoEnvironmental Sciences, Chinese Academy of Sciences, Beijing 100085, China.

Email: lyh@rcees.ac.cn

Funding information

National Natural Science Foundation of China, Grant/Award Number: 41601015. Ministry of Science and Technology of China, Grant/ Award Number: 2012BAC08B01.

\begin{abstract}
Forest restoration policies are often implemented without the assessment of their full environmental impact. In this study, we investigated the challenges of vegetation greening resulted from forest restoration on water resource sustainability, using a model-based simulation in northwestern China. Four different vegetation scenarios and 25 future climate scenarios were employed using the Soil and Water Assessment Tool model. Results suggest that (a) the mean annual evapotranspiration changes from only $7.2 \%$ in the barren case to $100 \%$ in the forest case; however, it produced a $35.2 \%$ reduction in average annual streamflow and a $157 \%$ increase in soil water storage. The upstream vegetation greening caused the enhancement of water retention, while also creating great challenges for future downstream water resource sustainability; (b) seasonal effect was significant in that $100 \%$ forest case increased evapotranspiration ( $+40 \%)$ but it also reduced the streamflow $(-73 \%)$ compared to the barren case in growing season, which may exacerbate spring and summer drought; (c) changes of evapotranspiration and streamflow were only $0.3 \%$ and $-0.9 \%$ at $\mathrm{T}+3.9{ }^{\circ} \mathrm{C}$ when compared to the historic scenario in barren cases, while for all forest cases, variations were $3 \%$ and $-21.8 \%$, respectively; (d) vegetation greening induced more remarkable changes in hydrological components than those resulting from climate change. Our "what if" research provides new insights for promoting sustainable management of water resources and ecosystems in mountainous water source areas.
\end{abstract}

\section{KEYWORDS}

mountain ecosystem, streamflow, the SWAT model, vegetation greening, water resources sustainability

\section{1 | INTRODUCTION}

Sustainability has become an issue in environmental planning during the past several decades; however, scientists, land managers, and communities still face great challenges in protecting the environment from degradation at both local and global levels (Cash et al., 2003; Peterseil et al., 2004). Under this challenging context, forest restoration and conservation were implemented, and the dynamics of land and water resources use are central issues in the study of regional and global environmental changes and must be clearly understood before sustainability will become possible (Fischer \& Sun, 2001).
China, the world's most populous country and the fourth largest in land territory, has experienced a booming economy for decades. Its environmental problems are among the most severe of any major country (Liu \& Diamond 2005). During the 1990s, 38\% of China's total land area was considered badly eroded (Cao et al., 2011); water resource problems alone cost 2.3\% of China's GDP in 2008 (World Bank, 2009); the Chinese government was aware of the severe land degradation problems and has developed numerous programs to tackle them (Cao et al., 2011; Jiang, 2015). Six key forestry programs (Table 1) have made significant progress, as measured by indicators such as an increase in vegetation cover (Song et al., 2012) and a 
reduction in soil erosion (Feng et al., 2012). The scale and the magnitude of the investment make these forestry programs the largest ecological restoration programs in the world (Uchida et al., 2005). Within the last decade, the most significant vegetation greening trends were detected in the northern part of China (Lü et al., 2015).

Water is a limited commodity in arid and semiarid landscapes, and water availability is of the utmost importance under the vegetation greening context both now and in the future, although the adaption potential of climate change in regards to afforestation is mobilized to boost potential carbon sequestration (Jackson et al., 2005). However, the role of forest expansion and its impacts on the hydrological cycle-especially on water yield-are not yet fully understood and thus remain hotly contested and questioned (Greeff, 2010). Many studies have demonstrated that forest plantation can significantly affect streamflow by altering its pattern, magnitude, and frequency (Ellison et al., 2012; Lacombe et al., 2016). One view concluded that the impact of afforestation on water yield is negative, indicating that additional plantation will reduce downstream water availability. Jackson et al. (2005), for example, found that forest plantation dramatically decreased streamflow by $227 \mathrm{~mm}$ per year globally $(52 \%)$, with $13 \%$ of streams drying completely for at least 1 year. Greeff (2010) and McVicar et al. (2007) arrived at similar conclusions; in arid and semi-arid zones, they suggested that forest plantation increased interception and evapotranspiration, therefore reducing streamflow and leading to declining water availability. Another view suggested that plantation may have positive effects on water yield at the regional and global levels (Greeff, 2010). Coe et al. (2009) and Silva et al. (2009) both presented similar findings at the global and regional scale; they argued that reductions in evapotranspiration from deforestation should imply reductions in precipitation, therefore increasing low streamflow events and drought.

The Qilian Mountains in northwestern China are the origin of several key inland rivers, including the Heihe, Shiyang, and Shule Rivers. They provide critical water supply to the downstream oases. Due to forest restoration and water conservation, vegetation normalized difference vegetation index has increased and has demonstrated the vegetation greening trend over the past decade (Song et al., 2012). However, environmental problems such as seasonal shortage of water supply emerged at the same time. $\mathrm{Yu}$ et al. (2010) argued that a $10 \%$ increase in vegetation greening led to reduction of $13 \%$ of streamflow at the watershed scale. In addition, temperatures have increased by $0.86{ }^{\circ} \mathrm{C}$ during the past four decades and are expected to continue rising in the future; this rise in temperature will therefore add constraints on the existing water management system (Leung et al., 2004). This area is sensitive to changes in climate due to its high elevations (Cui \& Wei, 2012).

Climate change raises the stakes in terms of future water availability (Leung et al., 2004). As previously mentioned, the relationship between vegetation and water budgets in catchments has been widely studied, but very few studies addressed the effects of vegetation greening on water balance in mountain areas. Researchers have speculated that vegetation greening and climate

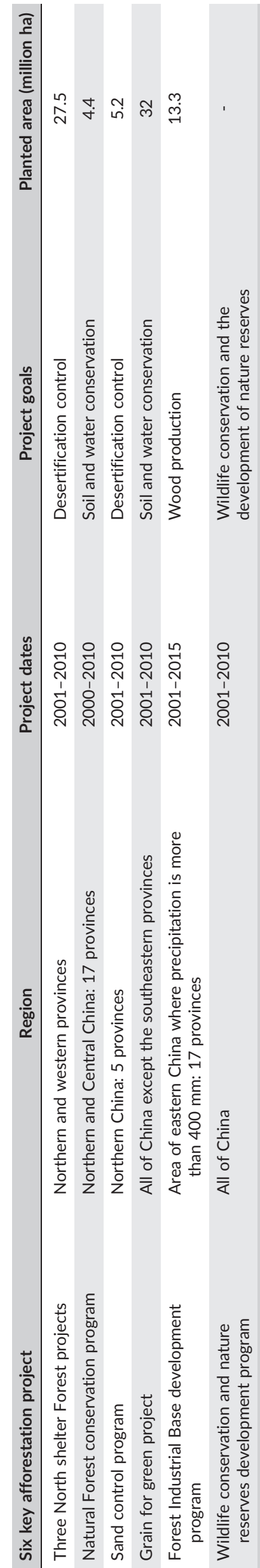


warming will change the water budget and create great challenges for downstream water resource sustainability. The forestation context is considered more sensitive to climate warming than a barren context, but this assumption has not been systematically proven. Our work here may provide valuable information on how water resources will develop in the future, guide administrations to plan reasonable forest restoration measures for possible future droughts under the context of climate warming, and finally, promote sustainable management in terms of water resource ecosystem integrity for mountainous areas of water-limited environments.

The purpose of the present study is (a) to determine the effects of vegetation greening on key components of the water cycle in the upper Qilian Mountains, (b) to quantify and detect whether a forestation context is more sensitive to climate warming than a barren (total deforestation) context, and finally (c), to discuss forest restoration strategies for long-term water resource sustainability.

\section{2 | STUDY AREA AND DATASET}

\section{1 | Study area}

The upper Qilian Mountains are located in the arid regions of Northwest China, covering $9319 \mathrm{~km}^{2}$, with elevations ranging from 1985 to $4723 \mathrm{~m}$ a.s.l. (Figure 1). The mean annual temperature is $1.2{ }^{\circ} \mathrm{C}$, and the total annual precipitation amounts to $216 \mathrm{~mm}$, with $80 \%$ mainly occurring from May to October.

Major land use units in the mountains include grassland, forest, and farmland. The high coverage grassland (vegetation coverage $>50 \%)$, the medium coverage grassland $(20 \%$ < vegetation coverage $<50 \%$ ), and the low coverage grassland $(5 \%<$ vegetation coverage $<20 \%$ ) occupy $47.8 \%, 21 \%$, and $11 \%$ of the study area, respectively. Forest and farmland accounted for about $17.3 \%$ and $0.2 \%$, respectively, of the study area (Figure 2).

We selected the upper Qilian Mountains as a case study for investigation because (a) it is a high-elevation region and sensitive to climate
FIGURE 1 The location of upper Qilian Mountain and elevation zones. DEM = digital elevation model
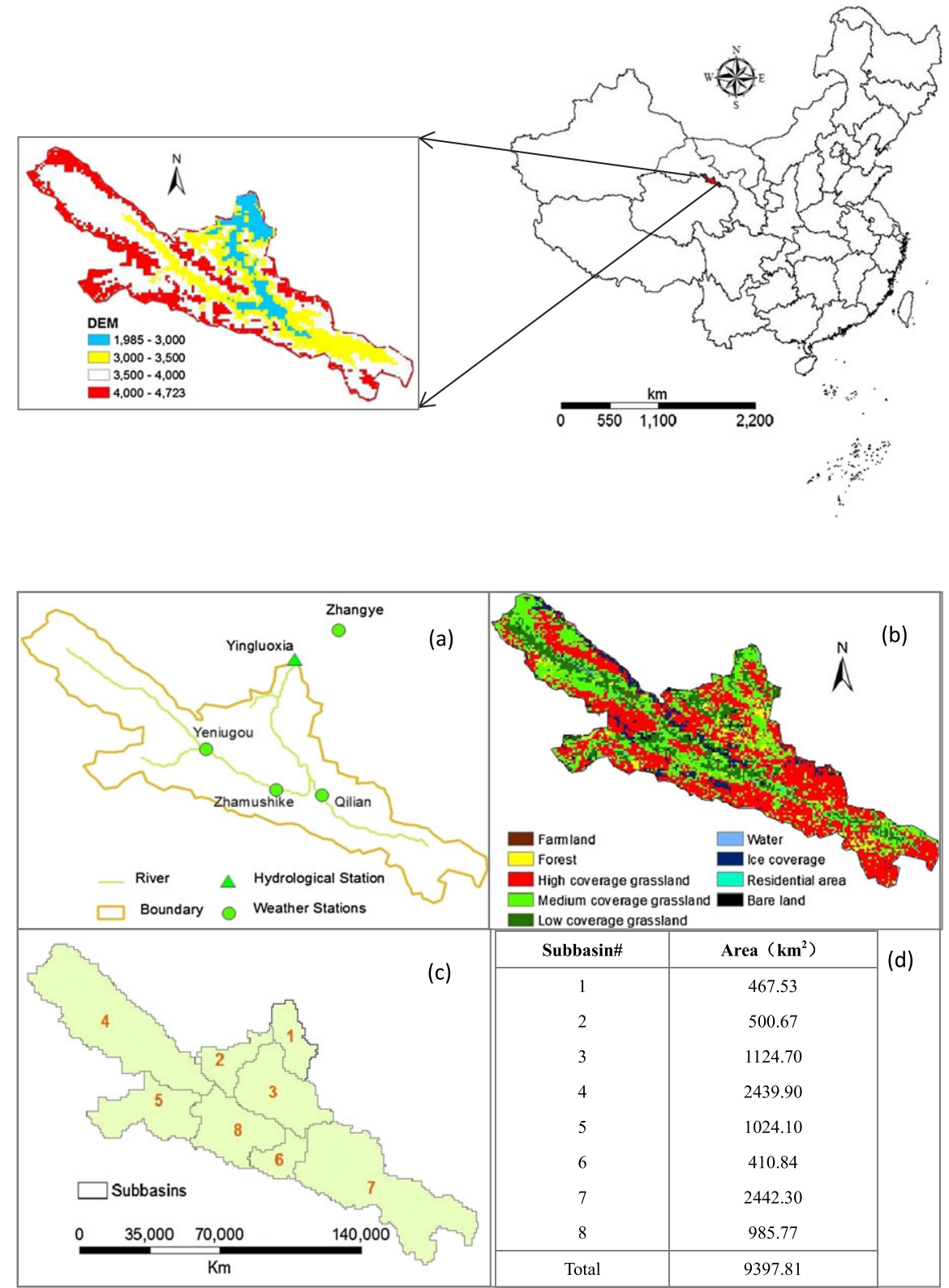

FIGURE 2 Soil and water assessment tool model input: (a) meteorological and hydrological stations, (b) land use, and (c) subbasin partition 
change, therefore raising the stakes with regard to future water availability; (b) many forest programs have been launched during the past decades; and (c) it is the main freshwater source for the downstream inland arid and semiarid territories; therefore, the study of the regional water cycle may have wide and important implications for water resource and ecosystem management in water-limited environments.

\section{2 | Datasets}

Daily meteorological data (including precipitation, wind speed, sunshine hours, relative humidity, maximum, minimum, and mean air temperatures) were collected from four rainfall gauges distributed in the study area (Figure 2). This data was obtained from the China Administration of Meteorology. Datasets covering 1970-2010 were used as inputs for hydrological simulation. Datasets of mean annual temperatures and total precipitation from 1970 to 2010 at the upper Qilian Mountains are presented in Figure 3. Annual precipitation decreased by $3 \%$ over a period of 10 years in the last decade. The mean annual air temperature increased by $0.86{ }^{\circ} \mathrm{C}$ during past four decades. Therefore, the study area has become drier and warmer.

Daily streamflow data from 1977 to 1987 and 1990 to 2010 were obtained from a hydrological control station (i.e., Yingluoxia; Figure 2) that is situated at the main outlet of the upper Qilian Mountains. The streamflow data was used in calibrating and validating the hydrological model. The streamflow data and the following digital elevation model, soil data, and land use data were all provided by the Heihe Data Research Group (http: www.westgis.ac.cn/datacenter.asp).

Digital elevation model data of $90 \mathrm{~m}$ spatial resolution was used to delineate the boundaries, river networks, and hydrologic response units. Information regarding soil type was extracted from a 1:1,000,000 digital soil map of the Heihe River Basin. Landsat TM images for 2010 with a spatial resolution of $30 \mathrm{~m}$ were regrouped into nine categories, namely, farmland, forest, high coverage grassland, medium coverage grassland, low coverage grassland, water, ice coverage, residential area, and bare land (Figure 2).

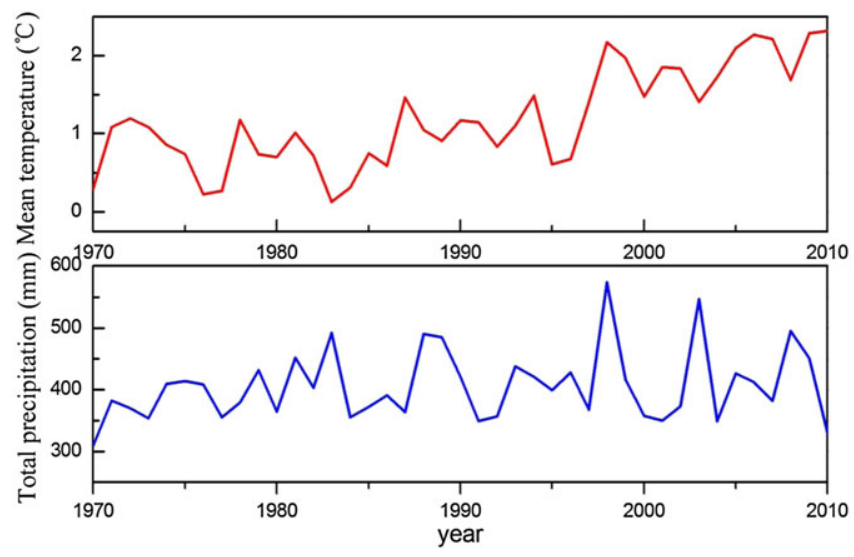

FIGURE 3 Mean annual air temperature and total precipitation at the upper Qilian Mountain during the period 1970-2010

\section{3 | METHODOLOGY}

\section{1 | Model used in the study}

Due to the difficulty in applying the paired-watersheds experimental approach to a large extent (greater than $1000 \mathrm{~km}^{2}$ ), modeling, isotopic method, and remote sensing techniques are normally used to assess the effects of land use change on hydrology (Cui et al., 2012). Different methods have different strengths and weaknesses, which are largely dependent on individual research objectives and the availability of high quality data (Cui \& Wei, 2012). The soil and water assessment tool (SWAT) model is a semi-distributed model developed by Arnold et al. (1998) and has been widely used; it has been successfully used in studies in the upper Qilian Mountains (Li et al., 2009). Therefore in this research, the SWAT model was applied to quantitative separation of the interactive influence on hydrology, and eight subbasins were identified (Figure 2).

\section{2 | Model calibration and validation}

Taking into account the availability of data, the monthly streamflow data for 1979-1987 were used to calibrate streamflow simulation; meanwhile, data from 1990 to 2004 were used for validation. This period was chosen because the first two years were used as warm-up period to mitigate the effects of unknown initial conditions, which were subsequently excluded from the analysis (Zang et al., 2012). On the basis of the sensitivity analysis tool in SWAT (Neitsch et al., 2004), we identified the 14 most sensitive parameters (Table 2). Note that many parameters in the SWAT model result in huge computational demand during calibration. To decrease the demand and to solve the problem of nonidentifiable parameters owing to strong overparameterization, we used the concept of "aggregate parameter" (Yang et al., 2008). In this way, 14 aggregate parameters (Table 2) are calibrated manually instead of the original parameters. All aggregate parameters are assumed to have uniform marginal prior distributions with specified ranges based on the SWAT manual (Yang et al., 2008). The performance of the model was evaluated by correlation coefficient $\left(R^{2}\right)$, Nash-Sutcliffe coefficients (Nash \& Sutcliffe, 1970), and relative error (RE).

The Nash-Sutcliffe coefficients are calculated as follows:

$$
E=1-\frac{\sum_{i=1}^{n}\left(Q_{m}-Q_{o}\right)^{2}}{\sum_{i=1}^{n}\left(Q_{m}-Q_{a v g}\right)^{2}}
$$

where $E$ is the Nash-Sutcliffe determinacy coefficient, $Q_{m}$ is simulated runoff $\left(\mathrm{m}^{3} / \mathrm{s}\right), Q_{0}$ is observed runoff $\left(\mathrm{m}^{3} / \mathrm{s}\right), Q_{\text {avg }}$ is the average observed runoff $\left(\mathrm{m}^{3} / \mathrm{s}\right), n$ is number of observed values, and $i$ is the index of the observed values. $E$ is used to estimate the agreement between the observed and simulated values. The range for $E$ is from negative infinity to 1 ; the nearer $E$ is to 1 , the more accurate the result.

Relative error was calculated as follows:

$$
R E=\left[Q_{o}-Q_{m} / Q_{o}\right] \times 100 \%,
$$

where $R E$ is the relative error, $Q_{m}$ is simulated runoff $\left(\mathrm{m}^{3} / \mathrm{s}\right)$, and $Q_{0}$ is observed runoff $\left(\mathrm{m}^{3} / \mathrm{s}\right)$. The smaller the $R E$, the better the result. 
TABLE 2 The best parameters and values used in the study

\begin{tabular}{|c|c|c|}
\hline Aggregate parameter $^{a}$ & Description & Best parameter value \\
\hline$r_{-} \mathrm{CN} 2$ & Initial SCS CNIIvalue & 0.51 \\
\hline v_ALPHA_BF & Base_flow alpha factor[days] & 0.94 \\
\hline v_GWQMN & Threshold water depth in the shallow aquifer for flow[mm] & 0.77 \\
\hline v_GW_REVAP & Groundwater "revap" coefficient & 0.098 \\
\hline r_SOL_AWC(1) & Availabile water capacity[mmH2Ommsoil-1] & 0.14 \\
\hline$r_{-} \mathrm{SOL}_{-} \mathrm{K}(1)$ & Maximum canopy storage $[\mathrm{mm}]$ & 0.23 \\
\hline v_SFTMP & Snowfall temperature $\left[{ }^{\circ} \mathrm{C}\right]$ & 0.79 \\
\hline v_SURLAG & Surface runoff lag time[days] & 4.68 \\
\hline
\end{tabular}

aThe parameters are constructed according to Yang's work (Yang et al., 2008). The " $v_{-}$" and "r $r_{-}$" means an increase, a replacement and a relative change to the initial parameter value, respectively.

Figure 4 shows the comparison of the simulated and observed monthly streamflow during the calibration and validation periods in the Yingluoxia gauges. The model performance during the validation period was better than calibration period, with high values of $R^{2}\left(R^{2}=0.96\right)$ and $E(E=0.93)$, and low relative error of $3.51 \%$. The coefficient of determination and Nash-Sutcliffe coefficient of calibration period were 0.93 and 0.88 , respectively, and the average value of relative error was only $5.68 \%$. These results demonstrate that the SWAT model generally exhibits a good performance for the upper Qilian Mountains.

\section{3 | Scenarios design}

To investigate changes in the hydrological cycle due to increasing temperatures and as a function of vegetation cover, four different scenarios with two extreme vegetation scenarios-all forest (forest

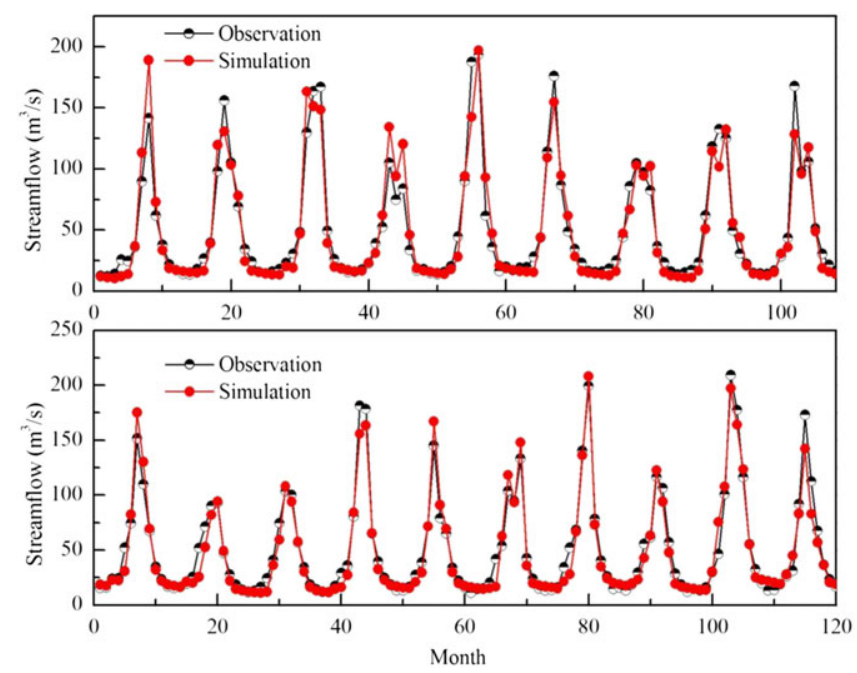

FIGURE 4 The soil and water assessment tool model hydrological calibration and validation. (a) Monthly observed and simulated streamflow during calibration period 1979-1987. (b) Monthly observed and simulated streamflow during validation period 1990-1999 cover $=100 \%$ ) and barren (forest cover $=0 \%$ )-at historic and a medium-high emissions scenario (A2, $3.9^{\circ} \mathrm{C}$ warming; IPCC, Intergovernmental Panel on Climate Change, 2001) are summarized in Table 3. These scenarios were considered to address the question of whether a forest case is more sensitive to warming than a barren case. In the upper Qilian Mountains, it is impossible to develop plantation forests on a large scale. Most of the forest is natural secondary forest, and therefore the scenario "all forest" in this research is mainly the natural forest.

On the basis of various GCMs, global mean temperature is projected to increase by a wide range (i.e., $1.4-5.8^{\circ} \mathrm{C}$ ) for the period between 1990 and 2100. Projected regional climate changes have great uncertainty. According to temperature and precipitation changes in the region over the last four decades with a medium-high emissions scenario, the temperature scenarios were generated by adding +0.86 , $+1.5,+2.5$, and $+3.9^{\circ} \mathrm{C}$ to the monthly baseline temperature, and the precipitation scenarios were generated by a factor of $0 \%, \pm 10 \%$, and $20 \%$, accumulating them to the monthly precipitation. Thus the combination of the temperature and precipitation series resulted in 25 climate change scenarios (Table 4). Basic data of land cover were adapted to land cover data in the year 2010. To explore the effects of climate change and vegetation greening on hydrological cycle, the results aimed to allow comparisons with the simulation run using four vegetation scenarios. In projecting hydrological cycle and water use sustainability, we had to rely on the assumption that the model calibrated against past records is applicable to future scenarios (Wattenbach et al., 2007).

TABLE 3 Four combined vegetation and climate scenarios in the upper Qilian Mountain

\begin{tabular}{|c|c|c|}
\hline Scenario & Vegetation cover & Climate condition \\
\hline A & All forest & Historic temperature, precipitation \\
\hline B & All forest & $\begin{array}{l}\text { Historic Temperature }+3.9^{\circ} \mathrm{C} \text { 、 } \\
\text { precipitation }\end{array}$ \\
\hline C & Barren & Historic temperature, precipitation \\
\hline $\mathrm{D}$ & Barren & $\begin{array}{l}\text { Historic Temperature }+3.9^{\circ} \mathrm{C} \text {. } \\
\text { precipitation }\end{array}$ \\
\hline
\end{tabular}


TABLE 4 Resulting climate change scenarios in the upper Qilian Mountain

\begin{tabular}{rrrcccc} 
& & \multicolumn{5}{c}{ Temperature } \\
\cline { 3 - 7 } & & $\mathbf{0}^{\circ} \mathbf{C}$ & $+\mathbf{0 . 8 6 ^ { \circ } \mathrm { C }}$ & $\mathbf{+ 1 . 5 ^ { \circ } \mathbf { C }}$ & $+2.5^{\circ} \mathbf{C}$ & $+3.9^{\circ} \mathbf{C}$ \\
\hline Precipitation & $-20 \%$ & S1 & S2 & S3 & S4 & S5 \\
& $-10 \%$ & S6 & S7 & S8 & S9 & S10 \\
O & S11 & S12 & S13 & S14 & S15 \\
& $10 \%$ & S16 & S17 & S18 & S19 & S20 \\
& $20 \%$ & S21 & S22 & S23 & S24 & S25
\end{tabular}

\section{4 | RESULTS AND DISCUSSION}

\section{1 | Effects of vegetation greening on major hydrological components}

Figure 5 shows the comparisons between the simulated streamflow, soil water storage, and evapotranspiration under different vegetation scenarios with optimized parameter values of the SWAT model in Table 2. Vegetation cover could affect streamflow magnitude. Usually an increase in precipitation was accompanied by an increase in streamflow. The modelled regression line for the all forest case (Scenario A) lies below that of the barren case (Scenario C); this implies that streamflow under the all forest case was much lower than in both the current vegetation and the all barren scenario while holding all other variables (i.e., precipitation) constant. Under the all barren scenario (Scenario C), average annual streamflow was estimated to be $31.6 \mathrm{~mm}$. If we consider the all forest Scenario $\mathrm{A}$, the average annual streamflow reduced to $20.4 \mathrm{~mm}$, representing a 35.2\% reduction (Figure 5). The streamflow reduction could be $25 \%$ in the $100 \%$ forest case in comparison with the current forest case. The variation was confirmed by $\mathrm{He}$ et al. (2012), who modelled the water balance to assess the contribution of different vegetation types to annual streamflow in the Pailugou catchment of the region (about $2.7 \mathrm{~km}^{2}$ ), and concluded that forest, grassland, and bare land contributed $3.5 \%$,
$59 \%$, and $33 \%$ of total annual streamflow, respectively, and that the forests decreased net water yield.

The increase in forest cover area changes the mean annual water balance through an increase in evapotranspiration (Figure 5). Evapotranspiration, as the largest component of the regional water balance, changes only slightly at $7.2 \%(11.85 \mathrm{~mm})$ between the barren case and the $100 \%$ forest case in the annual average over the entire simulation period. This change, however, has a strong influence on other components of the water balance, especially for the aforementioned streamflow.

He et al. (2012) revealed that about $8.1 \%$ of the precipitation was stored in soil to sustain forest growth in the same study area. Our simulation further indicated that soil water storage could increase by $157 \%$ and $48 \%$ in the $100 \%$ forest and the current forest case, respectively, in comparison with the barren case (Figure 5). As expected, forest expansion could potentially result in a drier downstream environment, but also increased soil water storage and played an important role in local water retention, promoting vegetation development.

Additionally, our research further indicated that forest expansion has much more obvious seasonal effects (Figure 6). Forest expansion leads to a $40 \%$ increase in evapotranspiration in the growing season (March-September), which incurs strong feedback to other hydrological components. Growing season has the highest amount of rainfall and is therefore quite important for soil water storage capacity and streamflow. Figure 6 indicates that this increase of evapotranspiration $(+40 \%)$ clearly influences the streamflow $(-73 \%)$, as well as the soil water storage capacity $(+76 \%)$ at $100 \%$ forest case when compared to the barren case in growing season. The change magnitude was especially pronounced in July, when streamflow decreased by $35.7 \%$ due to a strong evapotranspiration increment (16.5\%). Therefore, forest expansion may induce higher risks of spring and summer drought. Besides, forest expansions have increased soil water retention
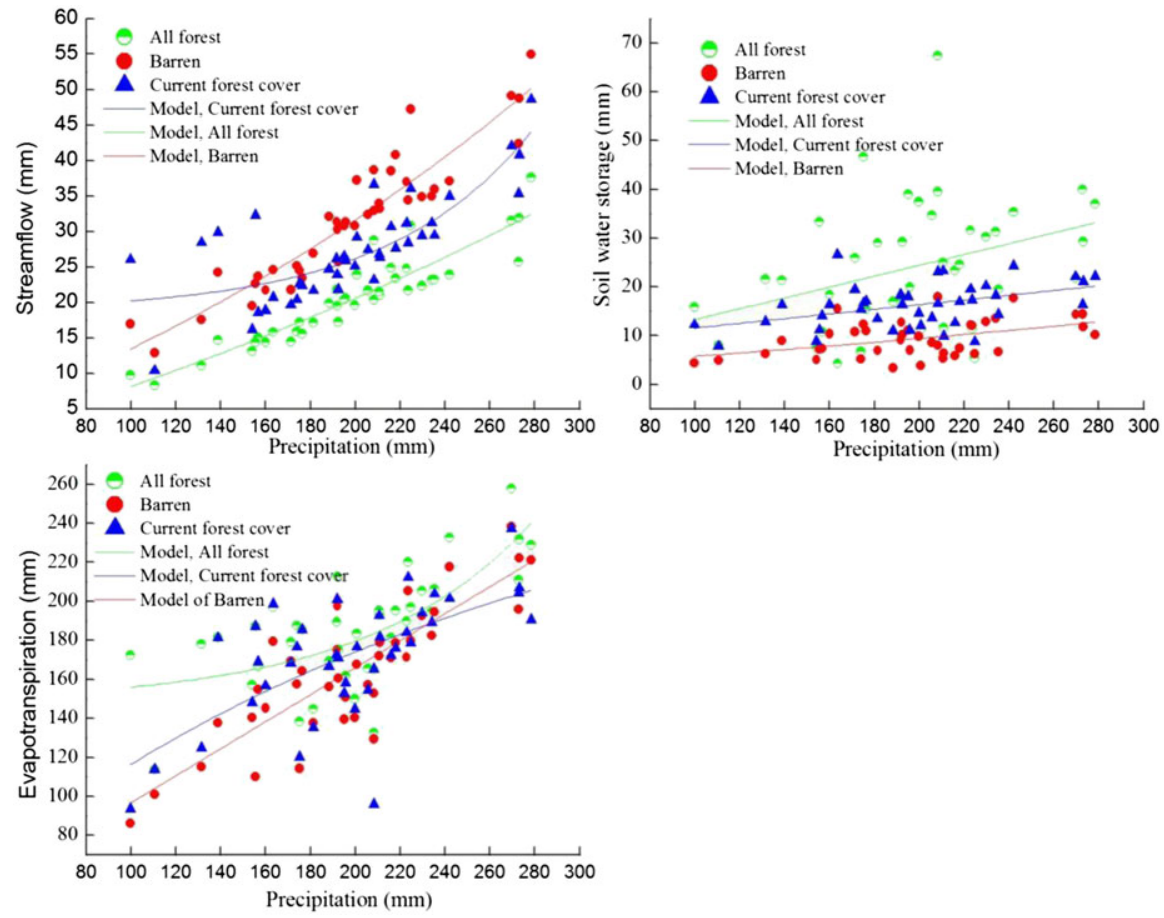

FIGURE 5 Comparisons of modelled annual streamflow, soil water storage, and evapotranspiration for all forest scenario, current forest cover scenario, and barren scenario for the upper Qilian Mountain 

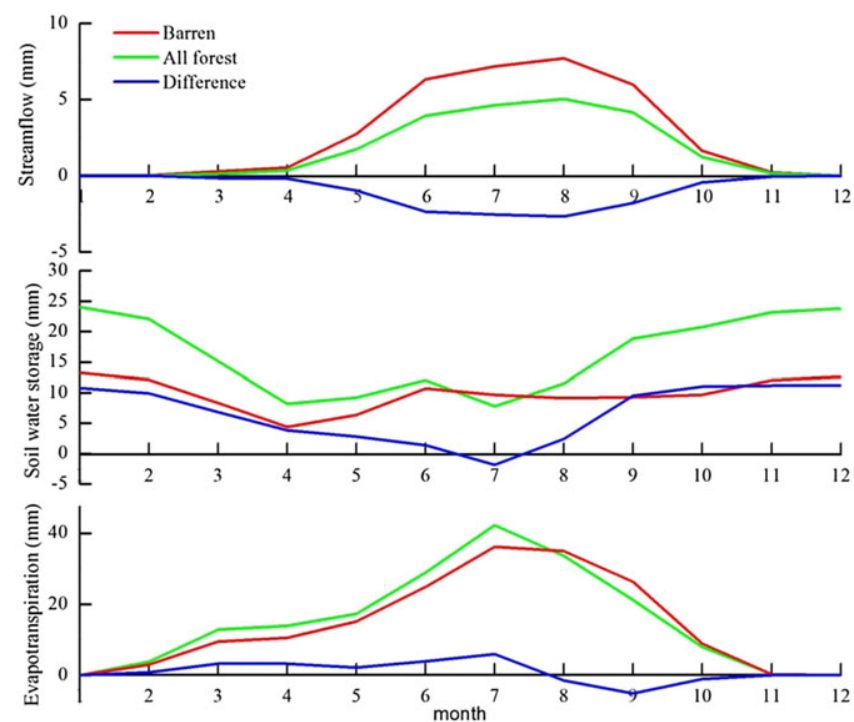

FIGURE 6 Changes in the monthly streamflow, soil water storage, and evapotranspiration caused by vegetation greening for the upper Qilian Mountain

capacity; a greater proportion of precipitation reaching the catchment is absorbed by the soil rather than flowing out of the region as runoff. Wattenbach et al. (2007) reported a $25.1 \%$ increase of evapotranspiration and a $22.1 \%$ reduction in streamflow in spring at $100 \%$ forest when compared to no forest. Our results appeared to be higher due to different regional backgrounds of land cover change scenarios. The land cover change in the present research is from grassland to forest, compared to the cropland to forest scenario reported by Wattenbach et al. (2007). Furthermore, grassland was reported to have higher evapotranspiration rates than cropland in the present research region (He et al., 2012).

\section{2 | Changes in hydrological components as a function of forest expansion in warming climate}

Comparisons of the hydrological components between forest and barren cases for the historic and warming temperatures during the validation period are presented in Figure 7. Results show that evapotranspiration and streamflow were predicted to change only $0.3 \%$, and $-0.9 \%$ at $\mathrm{T}+3.9^{\circ} \mathrm{C}$ when compared to the historic scenario

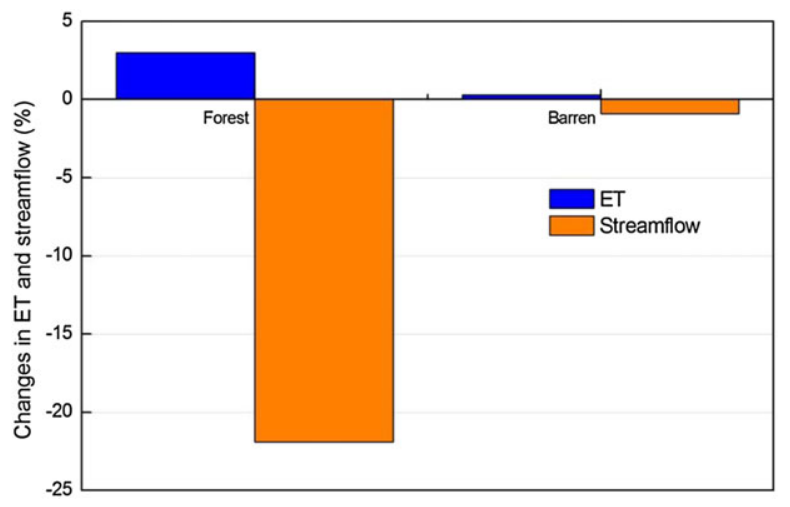

FIGURE 7 Changes in evapotransporation (ET), and streamflow in increasing temperature cased for all forest scenario and barren scenario during validation period of the upper Qilian Mountain in barren cases, while for all forest cases, predicted change in evapotranspiration was $3 \%$ and changes in streamflow were $-21.8 \%$, at $\mathrm{T}+3.9^{\circ} \mathrm{C}$ scenario when compared to the historic scenario. Obviously, the forest case is more sensitive under warming climate than the barren case. Land cover and climate change interactively affect hydrology, and climate feedbacks at regional scales could offset water losses through increased transpiration and convective rainfall; however, this may depend on site location and climate characteristics (Hoffmann \& Jackson, 2000). Zhang et al. (2012) disclosed that the increase of streamflow attributed to forest harvesting was $38 \mathrm{~mm} \mathrm{yr}^{-1}$, while the streamflow feedback attributed to climate variability was $-38.3 \mathrm{~mm} \mathrm{yr}^{-1}$, which suggests an offsetting effect between forest harvesting and climate variability in the Yellow River Basin. Based on field observations and modeling, Jackson et al. (2005) documented that forest plantations decreased $52 \%$ of streamflow globally and suggested that climate feedbacks were unlikely to offset such water losses and would instead exacerbate them. Our research further disclosed that forest expansion and climate warming showed reinforcing rather than offsetting effects on streamflow.

Sun et al. (2008) showed that high mountain vegetation was more vulnerable to warming impacts, as temperature increased vegetation activity and associated evaporative water loss. Water availability due to forest plantation would decrease with increasing temperature or increasing aridity from semihumid regions to arid regions (Sun et al., 2008). On average, global surface temperatures have increased about $0.74{ }^{\circ} \mathrm{C}$ over the past 100 years, with the higher temperature resulting in global increases of evapotranspiration, which may lead to decreased runoff (Jeppesen et al., 2009). In the present study area, the temperature increase $\left(0.86^{\circ} \mathrm{C}\right)$ was more significant than that at the global level. Along with future warming, forest expansion will intensify the pressure and challenges of water resource sustainability in the study area and its downstream drylands. These changes will exert significant impacts on economic development, particularly for the agricultural and water resources departments, at regional scales. Future research and water resource management need to consider these dynamic and interactive effects (Wattenbach et al., 2007).

\subsection{Changes in hydrological components under climate change}

Variations of the annual evapotranspiration, streamflow, and soil water storage under 25 future climate change scenarios are presented in Figure 8 . These indicate that annual hydrological components presented high variability under different climate scenarios. The precipitation of elasticity of streamflow in the upper Qilian Mountains is estimated to be 1.5 , indicating that a $10 \%$ change in precipitation will result in a 15\% change in streamflow in the current land use scenario, which is a little bit lower than that of the whole Yellow River Basin (Zheng et al., 2009). For evapotranspiration, although the variation magnitude was not as noticeable as that in streamflow, it also experienced great change, especially in the $-20 \%$ precipitation scenario, where the mean annual evapotranspiration presented a decrease of $19 \%$. Correspondingly, the largest evapotranspiration increase occurred in Scenario 25, with a magnitude of $18.3 \%$. Precipitation recharged more water into the soil, and soil water storage was 


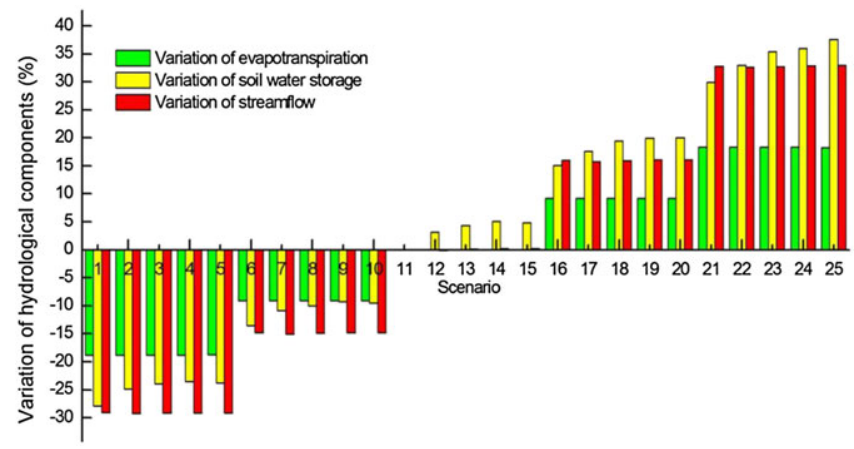

FIGURE 8 Variations of the annual evapotranspiration, soil water storage, and streamflow under 25 future climate scenarios

therefore simulated to increase about $37 \%$ in the $20 \%$ precipitation scenario when compared to that in the baseline period (Scenario 11). Hydrological components seem to be more sensitive to precipitation than temperature in this study area. However, it should be noted that uncertainties still existed, as the quantification is based on the assumption that the land use and land cover change used in this study are independent of climate change, while in fact, land surface and the climate system interact with each other. There is little doubt that climate change may play an important role and consequently change streamflow and other hydrological components.

\subsection{Potential risks of vegetation greening on water resources sustainability}

Based on 25 climate scenarios and 4 extreme land cover scenarios, results indicated that climate change plays an important role in regional hydrology, especially its remarkable effects on soil water storage and streamflow. Per the aforementioned discussion, the maximum increase magnitude of soil water storage was about $37 \%$ while precipitation increased $20 \%$, presenting a huge potential for water retention for vegetation use. However, the vegetation greening could produce $157 \%$ more soil water storage in the $100 \%$ forest cases than that found in barren cases. Meanwhile, the $100 \%$ forest case also produced $35 \%$ streamflow reduction. Therefore, changing magnitude in soil water storage and streamflow caused by vegetation greening was more remarkable than that produced by climate change.

Tradeoff, summarized by Jackson et al. (2005) as more trees equaling less water and fewer trees equaling more water, was tested in the present study. While vegetation greening causes enhancement of upstream water retention in ecosystems, it may still cause adverse side effects for freshwater provision and incur great challenges for future water resource sustainability, especially for dryland areas. Reduced water discharge to the downstream areas led to ecological degradation, such as the dieback of the riparian forests, the dry-up of the West and East Juyanhai lakes (Cheng et al., 2006), and the $1 \mathrm{~m}$ decline of the groundwater table in the downstream Ejina Delta that intensified desertification and the occurrence of sandstorms (Guo et al., 2009). Therefore, increased vegetation greening at the cost of decreased water supply needs to garner more attention, especially for long-term and regional scale water resource sustainability (Bruijnzeel, 2004; Jackson et al., 2005).
The debates between different schools of thought regarding the relationship between reforestation and water quantity may attribute to the fact that they address questions fundamentally at different spatiotemporal scales. Paired-catchment research provides evidence for a negative relationship between forest expansion and water quantity, even though research suggests increasing precipitation and runoff through reforestation at larger scales (Cui \& Wei, 2012). Globally, the dry extremes are projected to become more severe in areas where the mean precipitation is projected to decrease under future climate warming scenarios (Meehl et al., 2007). More research should be conducted in semiarid regions to ascertain whether this conclusion is universal or local. The dual characteristics of increased water use and higher soil water storage quantified above in this research are informative for policy makers concerning the tradeoffs on the environmental costs and benefits of forest management. Massive forest restoration efforts listed in Table 1 have been less effective than expected. Lü et al. (2015) used a remote sensing method to disclose that China experiences both vegetation greening (restoration) and browning (degradation) with great spatial heterogeneity. Water is the most important factor limiting vegetation growth, and large-scale forest restoration tends to exacerbate water shortages-especially in northwestern China. Great efforts of costly water transfer projects have been planned and are partly in the process of implementation to mitigate water shortages in the northern part of China (Liu et al., 2005).

The main contribution of our research is that it provides valuable information on how water resources develop under forest restoration and within the climate warming context for the future of mountainous areas in water-limited environments. The results imply that vegetation greening raises a complex set of issues and risks around governance. For instance, the upstream might be tempted to use the water to increase its biomass production in forestry to maintain water retention function; this can affect the quantity of water discharged to the downstream areas. Competing demands and tradeoff in water resource management demonstrates that it could be impossible to fulfill all needs at all times. In particular, there is a "serious risk of upstream/downstream conflict," not only between countries, but also within countries; such conflicts are growing, especially in arid and semiarid regions (Ashton, 2000). Although much less dramatic, the downstream consequences of upstream activities in the Murray-Darling Basin in Australia are also illustrated (Zhang et al., 2001). The upstream land use will affect the timing, frequency, and quantity of water flows (Ashton, 2000). What happens in terms of land use, water regulation, and diversions is of vital interest to those who live downstream. Proper attention must be paid to this issue in order to avert the recurrence of downstream desiccation, as recently witnessed (Guo et al., 2009).

In spite of the many statements regarding water retention and water scarcity resulting from vegetation greening, there is surprisingly little relevant research referring to and quantifying this issue; any conclusions about the topic-especially under unpredictable future scenarios-tends to be piecemeal and the upstream influences on the downstream communities remain relatively unexplored. Literature usually addresses the direct use of blue water branch available in aquifers and rivers for societal use; however, the largest water use is the consumptive use of green water in the evapotranspiration process 
involved in plant production (Zang et al., 2012). Water plays a fundamental role in supporting the ecosystem service, which is indispensable for a sustainable society. It also associated, directly or indirectly, with different types of ecosystem services, including biomass production, interception, and sedimentation (Lü et al., 2015). For a sound and balanced sustainable development of upstream-downstream dimensions, a full understanding of the interactions between land and water and a better coordination and integration between various sectors and interests is imperative and has important management implications. The increasing necessity of water resource preservation make it particularly important to develop mechanisms of reconciling upstream-downstream conflicts of interest in inland river basins, especially as intensified upstream biomass production increases the green-water return flow to the atmosphere, therefore decreasing the flow in the blue water branch. In the end, this easily produces downstream river depletion and develops unexpected side effects of water resource sustainability.

There is no escape from the fact that the demand for vulnerable water will continue to expand and so will competition for it, especially in arid and semiarid regions. Water sustainability issues related to vegetation greening will become even more important for the lives and activities of people (Grayman et al., 2012); these issues also have associated social, political, and ecological implications (Cosgrove \& Loucks, 2015). More uncertainty and more rapid return flows of water to the atmosphere are expected due to the current stage of the massive forest restoration effort and that which will occur in the future. Given the changes in the hydrologic cycle as result of land use and climate changes, the patterns of future water use-especially the upstream and the downstream interest-will become more severe. Further research is needed to better understand how these complex interactions may develop over the coming decades.

\section{5 | CONCLUSION}

Forest restoration is often implemented without full assessment of possible environmental impacts. In this study, we investigated the challenge of vegetation greening on water resource sustainability, from a model-based simulation in an area in northwestern China that is subject to severe water shortage problems. The following conclusions can be drawn from this study:

1. The mean annual evapotranspiration changes only $7.2 \%$ from barren case to $100 \%$ forest case; however, it produced a $35.2 \%$ reduction in average annual streamflow and a $157 \%$ increase in soil water storage. Vegetation greening caused an enhancement of ecosystem water retention in the upstream mountainous areas, while also creating great challenges for future downstream water resource sustainability in order to decrease freshwater discharge.

2. The changes of evapotranspiration and streamflow were only $0.3 \%$, and $-0.9 \%$ at the $\mathrm{T}+3.9{ }^{\circ} \mathrm{C}$ scenario when compared to the historic scenario in barren cases. For all forest cases, however variations were $3 \%$, and $-21.8 \%$. Forest cases are more sensitive in warming climates than barren cases. Forest expansion and climate warming played reinforcing roles rather than having offsetting effects on streamflow, which will reinforce the pressure on future water resource sustainability.

3. Changing magnitude in hydrological components caused by vegetation greening was quite more remarkable than that produced by climate change.

From a long-term perspective, our "what if" research provides new insights into the potential effects of vegetation greening under warming future upon water resources sustainability, particularly in water-limited environments. These results may inform administrations when planning reasonable forest restoration measures that will be adaptive to possible future droughts under the context of climate warming and will promote sustainable water resources and ecosystem management in headwater areas for drylands, as in the typical mountainous areas investigated in this research. However, it must be kept in mind that such conclusions are conditional upon the availability of the climate scenarios and approaches used in this research.

\section{ACKNOWLEDGMENTS}

We acknowledge, with gratitude, the financial support from the Ministry of Science and Technology of China (2012BAC08B01), the International Postdoctoral Exchange Fellowship Program (20130002), and the National Natural Science Foundation of China (41601015).

\section{REFERENCES}

Arnold, J. G., Srinivasan, R., Muttra, R. S., \& Williams, J. R. (1998). Large area hydrologic modelling and assessment part I: Model development. Journal of American Water Resources Association, 34, 73-89.

Ashton, P. J. (2000). Southern African water conflicts: are they inevitable or prevent-able? In H. Solomon, \& A. R. Turton (Eds.), Water wars: enduring myth or impending reality ()Africa Dialogue Monograph Series No. 2. (pp. 62-105). Durban, South Africa: The African Centre for the Constructive Resolution of Disputes (ACCORD).

Bruijnzeel, L. (2004). Hydrological functions of tropical forests: Not seeing the soil for the trees? Agriculture, Ecosystems and Environment, 104, 185-228.

Cao, S. X., Chen, L., Shankman, D., Wang, C. M., Wang, X. B., \& Zhang, H. (2011). Excessive reliance on afforestation in China's arid and semi-arid regions: Lessons in ecological restoration. Earth-Science Reviews, 104, 240-245.

Cash, D. W., Clark, W. C., Alcock, F., Dickson, N. M., Eckley, N., Guston, D. H., ... Mitchell, R. B. (2003). Knowledge systems for sustainable development. PNAS, 100, 8086-8091.

Cheng, G., Xiao, H., Xu, Z., \& Li, J. (2006). Water issue and its countermeasure in the inland river basins of Northwest China: A case study in Heihe River basin. Journal of Glaciology and Geohydrology, 28, 406-413.

Coe, M. T., Costa, M. H., \& Soares-Filho, B. S. (2009). The influence of historical and potential future deforestation on stream flow of the Amazon River-Land surface processes and atmospheric feedbacks. Journal of Hydrology, 369, 165-174.

Cosgrove, W. J., \& Loucks, D. P. (2015). Water management: Current and future challenges and research directions. Water Resources Research, 51, 4823-4839. doi:10.1002/2014WR016869

Cui, X., \& Wei, X. (2012). Impacts of forest changes on hydrology: A case study of large watersheds in the upper reaches of Minjiang River watershed in China. Hydrology and Earth System Sciences, 16, 4279-4290.

Ellison, D., Futter, M. N., \& Bishop, K. (2012). On n the forest cover-water yield debate: From demand- to supply-side thinking. Global Change Biology, 18, 806-820. 
Feng, X. M., Sun, G., Fu, B. J., Su, C. H., Liu, Y., \& Lamparski, H. (2012). Regional effects of vegetation restoration on water yield across the loess plateau, China. Hydrology and Earth System Sciences, 16, 2617-2628.

Fischer, G., \& Sun, L. X. (2001). Model based analysis of future land-use development in China. Agriculture, Ecosystems and Environment, 85, 163-176.

Grayman, W. M., Loucks, D. P., \& Saito, L. (Eds) (2012). Toward a sustainable water future: visions for 2050. Reston, Va: ASCE Press.

Greef, L. (2010). Thirsty tree plantations, no water left and climate confusion: What version of sustainable development are we leaving our children? A Geasphere collaboration with support from SNNC, http:// www.geasphere.co.za/articles/thirstytreesnowater.htm.

Guo, Q. L., Feng, Q., \& Li, J. L. (2009). Environmental changes after ecological water conveyance in the lower reaches of Heihe River, Northwest China. Environmental Geology, 58, 1387-1396.

He, Z. B., Zhao, W. Z., Liu, H., \& Tang, Z. X. (2012). Effect of forest on annual water yield in the mountains of an arid inland river basin: A case study in the Pailugou catchment on northwestern China's Qilian Mountains. Hydrological Processes, 26, 613-621.

Hoffmann, W. A., \& Jackson, R. B. (2000). Vegetation-climate feedbacks in the conversion of tropical savanna to grassland. Journal of Climate, 13, 1593-1602.

IPCC, Intergovernmental Panel on Climate Change. (2001). Special report on emissions scenarios, Chapter 4: An overview of scenarios/4.2. SRES scenarios Taxonomy/Table 4-2: Overview of SRES scenarios quantifications. (available at: http://www.grida.no/publications/other/ipcc_sr/ ?src=/climate/ipcc/emission/091.htm\#4.2.1.)

Jackson, R. B., Jobbagy, E. G., Avissar, R., Roy, S. B., Barrett, D. J., Cook, C. W., ... Murray, B. C. (2005). Trading water for carbon with biological carbon sequestration. Science, 310, 1944-1947.

Jeppesen, E., Kronvang, B., Meerhoff, M., Søndergaard, M., Hansen, K.M., Andersen, H.E., ... Olesen J.E. (2009). Climate change effects on runoff, catchment phosphorus loading and lake ecological state, and potential adaptations. Hydrobiologia, 663(1):1-21.

Jiang, Y. (2015). China's water security: Current status, emerging challenges and future prospects. Environmental Science \& Policy, 54, 106-125.

Lacombe, G., Ribolzi, O., de Rouw, A., Pierret, A., Latsachak, K., Silvera, N., ... Valentin, C. (2016). Contradictory hydrological impacts of afforestation in the humid tropics evidenced by long-term field monitoring and simulation modelling. Hydrology and Earth System Sciences, 20, 2691-2704.

Leung, L. R., Qian, Y., Bian, X. D., Washington, W. M., Han, J., \& Roads, J. O. (2004). Mid-century ensemble regional climate change scenarios for the western United States. Climatic Change, 62, 75-113.

Li, Z. L., Xu, Z. X., Shao, Q. X., \& Yang, J. (2009). Parameter estimation and uncertainty analysis of SWAT model in upper reaches of the Heihe river basin. Hydrological Processes, 23, 2744-2753.

Liu, J. G., \& Diamond, J. (2005). China's environment in a globalizing world. Nature, 435, 1179-1186.

Lü, Y. H., Zhang, L. W., Feng, X. M., Zeng, Y., Fu, B. J., Yao, X. L., ... Wu, B. F. (2015). Recent ecological transitions in China: Greening, browning, and influential factors. Scientific Reports, 5, 8732. doi:10.1038/srep08732

McVicar, T. R., Li, L. T., Niel, T. G., Zhang, L., Li, R., Yang, Q. K., ... Gao, P. (2007). Developing a decision support tool for China's re-vegetation program: Simulating regional impacts of afforestation on average annual streamflow in the loess plateau. Forest Ecology and Management, 251, 65-81.

Meehl, G. A., Covey, C., Taylor, K. E., Delworth, T., Stouffer, R. J., Latif, M., ... Mitchell, J. F. B. (2007). THE WCRP CMIP3 multimodel dataset: A new era in climate change research. American Meteorological Society, $88,1383-1394$

Nash, J. E., \& Sutcliffe, J. V. (1970). Riverflow forecasting through conceptual model. Journal of Hydrology, 10, 282-290.
Neitsch, S. L., Arnold, J. G., Kiniry, J. R., \& Williams, J. R. (2004).Soil and water assessment tool input/output file documentation version 2005 grassland, soil and water research laboratory Angriculture research services \& black land research center Texas Agricultual experiment station. 2004.

Peterseil, J., Wrbka, T., Plutzar, C., Schmitzberger, I., Kiss, A., Szerencsits, E., ... Beissmann, H. (2004). Evaluating the ecological sustainability of Austrian agricultural landscapes-The SINUS approach. Land Use Policy, $21,307-320$

Silva Dias, M. A., Avissar, R., \& Silva, D. P. (2009). Modeling the regional and remote climatic impact of deforestation. In M. Kel-ler, M. Bustamante, J. Gash, \& P. Silva Dias (Eds.), Amazonia and global change, Vol 186. (pp. 251-260). Washington, DC: AGU, Geophysical Mono-graph Series.

Song, X., Yan, C. Z., Xie, J. L., \& Li, S. (2012). Assessment of changes in the area of the water conservation forest in the Qilian Mountains of China's Gansu province, and the effects on water conservation. Environmental Earth Sciences, 66, 2441-2448.

Sun, G., Zuo, C., Liu, S., Liu, M., McNulty, S. G., \& Vose, J. M. (2008). Watershed evapotranspiration increased due to changes in vegetation composition and structure under a subtropic climate. Journal of American Water Resources Association, 44, 1164-1175.

Uchida, E. U., Xu, J. T., \& Rozelle, S. (2005). Grain for green: Cost-effectiveness and sustainability of China's conservation set-aside program. Land Economics, 81, 247-264.

Wattenbach, M., Zebish, M., Hattermann, F., Gottschalk, P., Goemann, H. Kreins, P., ... Wechsung, F. (2007). Hydrological impact assessment of afforestation and change in tree-species composition - A regional case study for the Federal State of Brandenburg (Germany). Journal of Hydrology, 346, 1-17.

World Bank. (2009). Addressing China's water scarcity. Recommendations for selected water resource management issues, $198 \mathrm{p}$. Washington.

Yang, J., Reichert, P., Abbaspour, K. C., Xia, J., \& Yang, H. (2008). Comparing uncertainty analysis techniques for a SWAT application to the Chaohe Basin in China. Journal of Hydrology, 358(1-2), 1-23.

Yu, P. T., Wang, Y. H., Wu, X. D., Dong, X. H., Xiong, W., Bu, G. W., ... Xu, L. H. (2010). Water yield reduction due to forestation in arid mountainous regions, Northwest China. International Journal of Sediment Research, $25,423-430$

Zang, C. F., Liu, J. G., Velde, M. V. D., \& Kraxner, F. (2012). Assessment of spatial and temporal patterns of green and blue water flows under natural conditions in inland river basins in Northwest China. Hydrology and Earth System Sciences, 16, 2859-2870.

Zhang, M. F., Wei, X. H., Sun, P. S., \& Liu, S. R. (2012). The effect of forest harvesting and climatic variability on runoff in a large watershed: The case study in the upper Minjiang River of Yangtze River basin. Journal of Hydrology, 464-465, 1-11.

Zhang, L., Dawes, W. R., \& Walker, G. R. (2001). Response of mean annual evapotranspiration to vegetation changes at catchment scale. Water Resources Research, 37(3), 701-708.

Zheng, H. X., Zhang, L., Zhu, R. R., Liu, C. M., Sato, Y., \& Fukushima, Y. (2009). Responses of streamflow to climate and land surface change in the headwaters of the Yellow River basin. Water Resources Research, 45. doi:10.1029/2007WR006665.WO0A19

How to cite this article: Tian F, Lü YH, Fu BJ, et al. Challenge of vegetation greening on water resources sustainability: Insights from a modeling-based analysis in Northwest China. Hydrological Processes. 2017;31:1469-1478. https://doi.org/10.1002/hyp.11118 